\title{
LEAN CONCEPT IN METAL ENTERPRISES - VERIFICATION OF BENEFITS
}

doi: 10.2478/cqpi-2019-0009

Date of submission of the article to the Editor: 26/04/2019

Date of acceptance of the article by the Editor: 20/05/2019

Marta Daroń1 -orcid id: 0000-0002-5000-0573

Monika Górska²-orcid id: 0000-0001-9774-4740

${ }^{1}$ Czestochowa University of Technology, Poland

${ }^{2}$ Czestochowa University of Technology, Poland

\begin{abstract}
In this paper there were presented some issues connected with Lean concept in improving of production processes. The research was conducted on the example of production enterprises that function in metal industry. The enterprises for the research were chosen purposefully, because of two reasons - the possibility to obtain information on the researched area and the assumption that these enterprises use the lean concept instruments. The questionnaire was the research tool. The goal of the research was to examine, what are the most expected advantages from implementing of lean concept methods, and what were the real advantages, that occurred in production system of researched enterprises. The authors presented the quantitative results of the study and carried out an analysis of the response in the form of a matrix. The developed matrix extended the knowledge about the distribution of observed benefits. It enables to indicate which advantages occurred in the enterprises expecting and not expecting some benefits.
\end{abstract}

Keywords: management, quality, lean management

\section{INTRODUCTION}

Nowadays, Toyota's contribution to the development of production systems is undeniable. It initiated many management techniques and tools known worldwide and successfully used today. Over the years, a significant number of studies on Toyota practices have been made, but by Womack, Jones and Roos the Toyota production system was denominated Lean Manufacturing (1990). On the basis of Lean Manufacturing used in manufacturing enterprises, it was created the Lean Management concept, which is also successfully used in service enterprises, eg. in the field of logistics, construction, finances or in public sector entities - in healthcare, local government, higher education, etc. Lean Management as a business concept is aimed towards minimizing the amount of both: company resources and the time that an enterprise needs to carry out tasks (Jewalikar, Shelke 2017). Thus, the main principle of Lean Management has become the reduction of all types of waste in transport, inventory, traffic, waiting, processing, production and defects (Schonberger 
2018). There are also many other benefits of using the Lean concept. For example, Jewalikar and Shelke (2017) differentiate the benefits of introducing Lean Integrated Management Systems into internal (organizational, financial and human) and external (financial, communication and systemic). However, it is noticed, that achieving specific benefits may have a different meaning for different entities.

Therefore, it was decided to check what benefits the companies introducing Lean Management instruments want to gain and whether some benefits were actually recorded. The main goal of the article was namely to check what are the most expected benefits arising from the use of the lean concept instruments, and what benefits have actually been observed in the scope of the production system in the surveyed enterprises.

The study was conducted in selected enterprises of the SME (small and mediumsized enterprises) sector of the metal industry. In order to achieve the goal of the paper, there were carried out questionnaires on the Lean approach and the effects of its implementation. The presented results relate to the production system. It should be noted that the paper presents only the partial results of the research. Achieving the research goal required the formulation of the main hypothesis, which is as follows: There are observed the expected benefits in companies using Lean concept instruments.

\section{METHODOLOGY}

Surveys were conducted in selected enterprises of the metal industry. There was used a questionnaire, consisting of a series of open-ended, closed and mixed questions and an imprint. The questionnaire form was addressed to managers of several dozen enterprises in the Śląskie and Łódź Voivodships, which intend to introduce the Lean concept ( $80 \%$ of surveyed entities) or have already implemented it ( $20 \%$ of entities). It was managed to obtain 14 completed questionnaires. However, after verifying the correctness of completing the questionnaires, 10 entities were used for the final analysis. The subjects were from the SME sector. Microenterprises (employing less than 10 employees) did not participate in the study. The mediumsized enterprises (employing less than 250 employees) predominated - 70\% of the surveyed facilities, and $30 \%$ constituted small enterprises (less than 50 people).

The implementation of the main objective required firstly to determine the benefits expected by managers in the field of the production system before the introduction of lean management instruments. At this point, the respondents had many suggested answers to choose, but also the option of entering their own. For better analysis, the answers were grouped into specific sets of benefits. This path was repeated in the development of response results regarding the benefits that were actually observed after the introduction of the lean concept in selected research entities. Respondents also answered questions about the types of Lean concept instruments used, the length of their application, the difficulty of introducing them and the willingness to continue their Lean improvement.

The second stage of data analysis included the preparation of a matrix which enables to present in detail the results of the study in terms of expected and achieved benefits. As a result, it was indicated which benefits (expected and unintended) did not occur at all, which occurred only some enterprises, and which in all enterprises. This gave a full picture of the distribution of responses and indicated further possible areas of research. 


\section{RESULTS}

In order to fully analyze the results of the research, the respondents' answers should be studied first of all regarding the expected and achieved benefits resulting from the implementation of Lean tools. Fig. 1 presents a collective statement of responses (the answers obtained have been combined into benefit groups) concerning the area of the production system. However, Table 1 shows the total distribution of responses. At the same time, the table contains only the benefits that were indicated by the respondents of the surveyed enterprises.

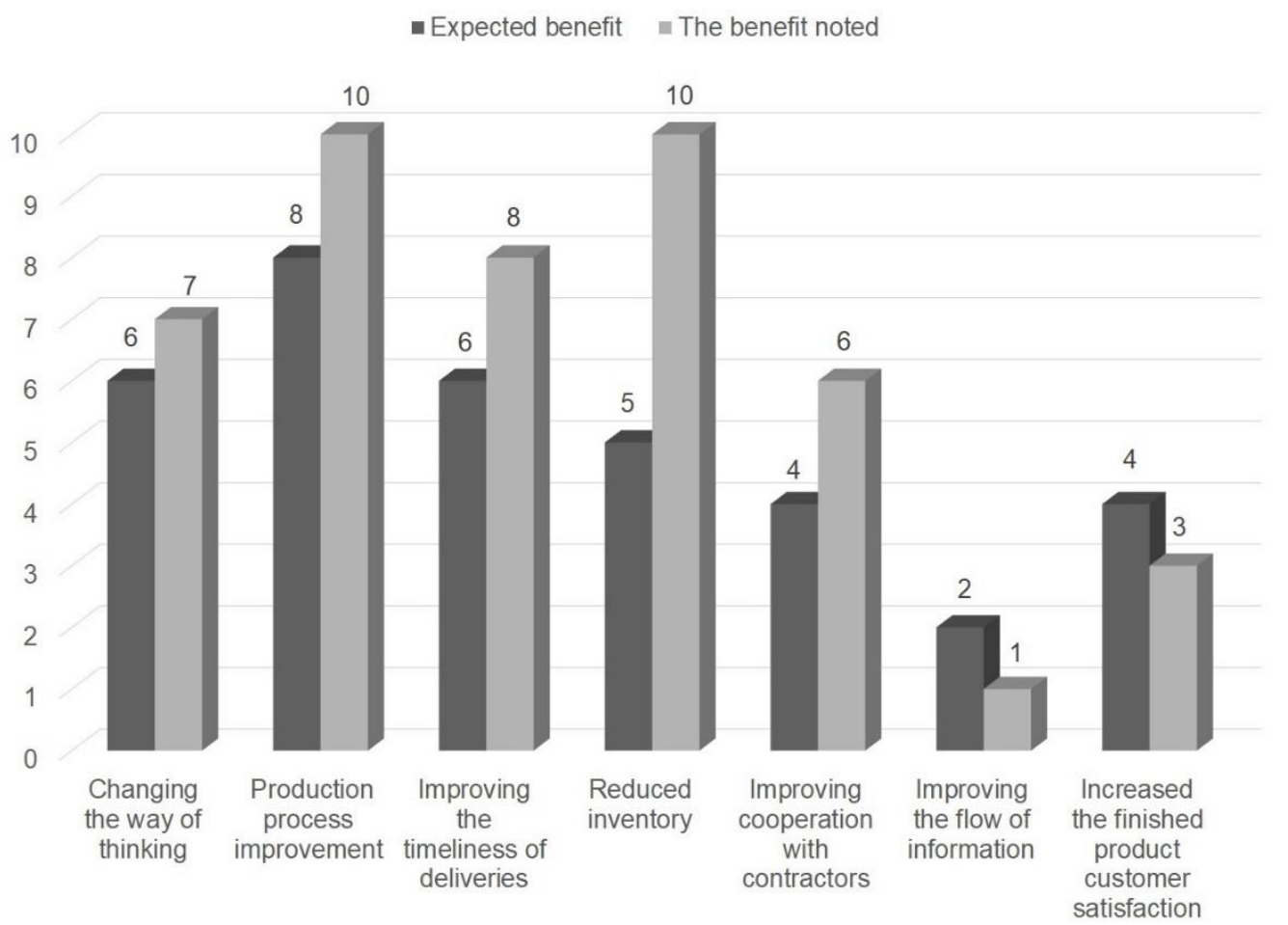

Fig.1. Expected and noted benefits Source: own study

Analyzing the data presented in Fig. 1, it can be seen that the majority of the surveyed entities expected improvement in the scope of the production process (8 indications). At the same time, these indications concerned at least one of the indicated benefits: Improvement and modernization of the production process, Improvement of quality, including health and safety, shortening of the production cycle, decrease in the number of complaints, Limitation of the number of incompatible products or shorter production time (tab.1). In this area, in one of the possible partial responses (decrease in the number of complaints), all enterprises noticed its occurrence. On the other hand, the smallest share of enterprises expected improvement in the scope of information flow. At the same time, this benefit did not occur for all of enterprises using it. Attention is also paid to the fact that only a small share of the surveyed enterprises is aware of the importance of the need to adapt the product to customer requirements. Only four of the surveyed entities expected benefits in terms of matching the product to customer requirements. The benefit was additionally present in one of the entities that did not expect it. 
Table1

A verification of noted benefits

\begin{tabular}{|c|c|c|c|c|c|c|}
\hline \multirow[b]{2}{*}{ Benefits } & \multicolumn{3}{|c|}{$\begin{array}{c}\text { Revision of the } \\
\text { occurrence of a benefit in } \\
\text { enterprises } \\
\text { that did not expect it }\end{array}$} & \multicolumn{3}{|c|}{$\begin{array}{c}\text { Revision of the } \\
\text { occurrence of a benefit } \\
\text { in enterprises } \\
\text { that expected it }\end{array}$} \\
\hline & 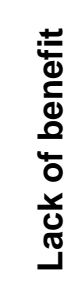 & 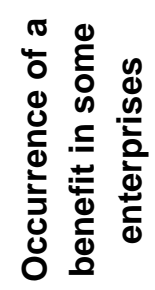 & 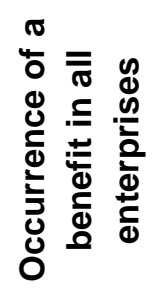 & 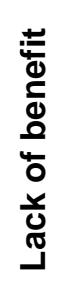 & 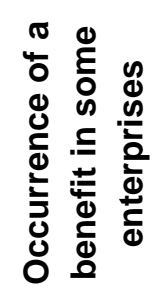 & 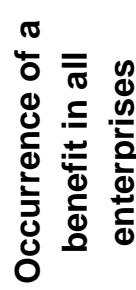 \\
\hline \multicolumn{7}{|c|}{ Material } \\
\hline $\begin{array}{l}\text { Improvement and modernization } \\
\text { of the production process }\end{array}$ & - & $\checkmark$ & - & - & $\checkmark$ & - \\
\hline $\begin{array}{l}\text { Improvement of quality, including } \\
\text { health and safety }\end{array}$ & - & $\checkmark$ & - & - & - & $\checkmark$ \\
\hline Shortening the production cycle & $\checkmark$ & - & - & - & $\checkmark$ & - \\
\hline $\begin{array}{l}\text { Decrease in the number of } \\
\text { complaints }\end{array}$ & - & - & $\checkmark$ & - & - & $\checkmark$ \\
\hline $\begin{array}{l}\text { Limiting the number of } \\
\text { incompatible products }\end{array}$ & - & $\checkmark$ & - & - & $\checkmark$ & - \\
\hline Shortening the time of production & $\checkmark$ & - & - & - & $\checkmark$ & - \\
\hline Shortening the time of delivery & - & $\checkmark$ & - & - & - & $\checkmark$ \\
\hline Reliability of deliveries & - & $\checkmark$ & - & - & $\checkmark$ & - \\
\hline $\begin{array}{l}\text { Optimization of production } \\
\text { inventories in progress }\end{array}$ & - & - & $\checkmark$ & - & - & $\checkmark$ \\
\hline Increase in production capacity & - & $\checkmark$ & - & - & $\checkmark$ & - \\
\hline $\begin{array}{l}\text { The increase in demand for } \\
\text { products }\end{array}$ & - & $\checkmark$ & - & - & $\checkmark$ & - \\
\hline \multicolumn{7}{|c|}{ Immaterial } \\
\hline $\begin{array}{l}\text { Increased competence and } \\
\text { responsibility of employees }\end{array}$ & - & $\checkmark$ & - & - & - & $\checkmark$ \\
\hline Increased teamwork skills & $\checkmark$ & - & - & - & $\checkmark$ & - \\
\hline $\begin{array}{l}\text { Changing the way of managers' } \\
\text { thinking }\end{array}$ & - & $\checkmark$ & - & - & $\checkmark$ & - \\
\hline $\begin{array}{l}\text { Changing the way of employees' } \\
\text { thinking }\end{array}$ & $\checkmark$ & - & - & & $\checkmark$ & \\
\hline $\begin{array}{l}\text { Improving cooperation with } \\
\text { suppliers }\end{array}$ & - & $\checkmark$ & - & - & - & $\checkmark$ \\
\hline $\begin{array}{l}\text { Increased efficiency of } \\
\text { information flow in the enterprise }\end{array}$ & $\checkmark$ & - & - & - & $\checkmark$ & - \\
\hline $\begin{array}{l}\text { Production of the product } \\
\text { regarding client's requirements }\end{array}$ & - & $\checkmark$ & - & - & $\checkmark$ & - \\
\hline
\end{tabular}

Source: own study 
The surveyed enterprises also answered the question regarding the will to continue the implementation of the Lean concept in the area of production process management (Fig. 2).

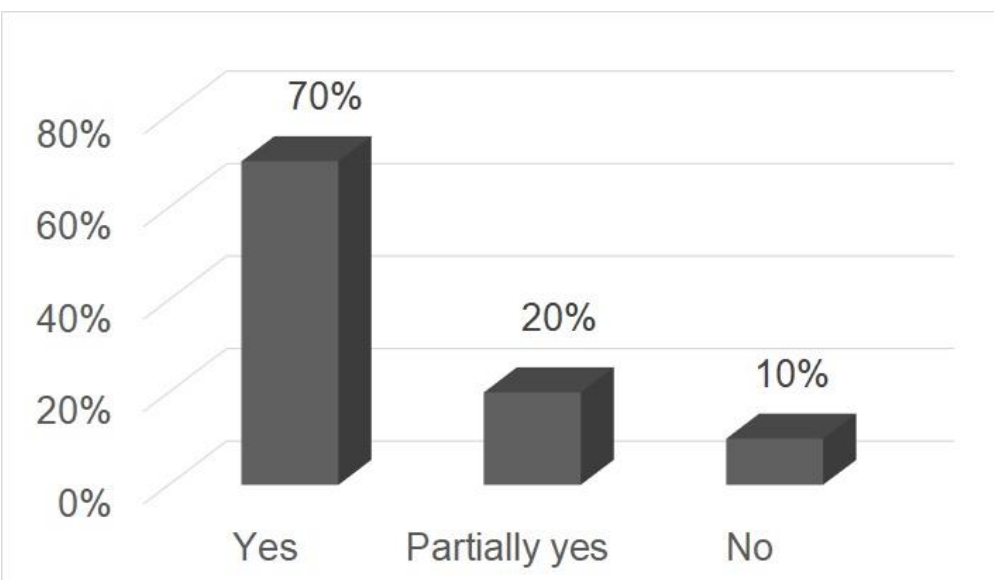

Fig. 2. The will to continue implementing Lean in the area of production process management Source: own study

Data analysis (Fig. 2) shows that further implementation of the Lean concept solutions was confirmed by as many as $70 \%$ of the surveyed entities, another $20 \%$ answered "partly yes", and only $10 \%$ of entities declared that they were giving up the further implementation of the "lean" approach. The results show that the implementation of the Lean concept is dictated not only for large corporations, but the effects of its implementation can bring many benefits also for small and medium-sized companies. It is worth adding that small enterprises have limited resources at their disposal, but the culture of continuous improvement over time will bring lasting results.

\section{DISCUSSION}

There are many studies in the literature showing the implementation model of the lean concept regarding achieving various benefits. For example, according to Werma and Sharma (2017), lean management improves productivity and quality. However, the benefits from improvements are only estimated values, not actual results. Karim and Arif-Uz-Zaman, on the other hand, verify achieving the benefits presented by the introduction of lean manufacturing using case study (2013). A similar approach is used by Klimecka-Tatar (2017) presenting the VSM method for a specific company. In turn, Baskiewicz i Kadłubek (2017) examine the impact of selected Lean Management tools on the individual effects of improving production processes. The research results presented in this paper indicate whereas specifically which of the benefits of Lean instruments selected from the literature are actually recorded by the surveyed enterprises. Moreover, based on the results of the study, it can be clearly indicated that some of the benefits also appear in those enterprises, where they were not expected. At the same time, it is noted that in some companies, despite the use of the Lean concept instruments, the expected benefits did not occur. This opens a series of questions related to the reasons for this situation. 


\section{CONCLUSION}

The implementation of the Lean concept is a multi-stage, time-consuming process that involves many techniques and methods of enterprise management. Many years' research and studies on the Toyota production system have shown, the implementation of the Lean concept involves the possibility of occurring of many barriers and obstacles. However, the benefits of proper implementation compensate for all the hardships and effort put into lean transformation.

The conducted research has shown, that the Lean concept is also applicable in small and medium-sized enterprises (SMEs). The results of tests carried out in selected entities of the metal industry clearly indicate this. Of course, the chosen research sample due to its size and selection method cannot be representative in relation to the entire metal industry. However, the presented results can be considered as an introduction to further research in this field. Furthermore, the goal of the paper, which was to verify the occurrence of the expected benefits from the introduction of the Lean concept instruments, was achieved. It was indicated that the expected benefits are usually recorded after the introduction of Lean tools, however, not in every case.

Attention is also drawn to the difficulties connected with the selection and implementation of appropriate Lean concepts. The larger the company, the more Lean management tools can be used at the same time. Small enterprises, on the other hand, may focus on choosing, for example, one improvement tool best suited to their business profile.

\section{REFERENCES}

Baskiewicz, N. Kadłubek, M. 2017. Wykorzystanie narzędzi Lean Management w celu doskonalenia procesu produkcyjnego wybranego przedsiębiorstwa, Prace Naukowe Uniwersytetu Ekonomicznego we Wrocławiu, 463, 121-131, DOI: 10.15611/pn.2017.463.10.

Jewalikar, D., Shelke, A. 2017. Lean Integrated Management Systems in MSME Reasons, Advantages and Barriers on Implementation, Materials Today: Proceedings, 4 (2) A, 1037-1044, DOI: 10.1016/j.matpr.2017.01.117.

Karim, A., Arif-Uz-Zaman, K. 2013. A methodology for effective implementation of lean strategies and its performance evaluation in manufacturing organizations, Business Process Management Journal, 19 (1), 169-196, DOI: 10.1108/14637151311294912.

Klimecka-Tatar, D., 2017. Value Stream Mapping as Lean Production tool to improve the production process organization -case study in packaging manufacturing, Production Engineering Archives, 17, 40-44, DOI: 10.30657/pea.2017.17.09.

Matwiejczuk, W. (ed.), 2009. Koncepcje i metody zarządzania, Oficyna Wydawnicza Politechniki Białostockiej, Białystok-Poland.

Schonberger, R. J., 2018. The disintegration of lean manufacturing and lean management, Business Horizons, BUSHOR-1553, DOI: 10.1016/j.bushor.2019.01.004

Verma, N., Sharma, V. 2017, Sustainable competitive advantage by implementing lean manufacturing "A Case study for Indian SME", Materials Today: Proceedings, 4 (8), 9210-9217, DOI: 10.1016/j.matpr.2017.07.279.

Womack, J.P., Jones D. T., Roos D., 1990. The Machine That Changed the World: The Story of Lean Production, Toyota's Secret Weapon in the Global Car Wars That Is Now Revolutionizing World Industry. Free Press, New York-USA. 